\title{
Reduced graphene oxide functionalized nanofibrous silk fibroin matrices for engineering excitable tissues
}

\author{
Guoxu Zhao ${ }^{1,2}$, Huaibin Qing ${ }^{2,3}$, Guoyou Huang ${ }^{1,2}$, Guy M. Genin ${ }^{1,2,4}$, Tian Jian Lu ${ }^{5,6}$, Zhengtang Luo ${ }^{7}$, Feng Xu ${ }^{1,2}$ and
} Xiaohui Zhang ${ }^{1,2}$

\begin{abstract}
Tissue engineering has provided an alternative strategy for the regeneration of functional tissues for drug screening and disease intervention. The central challenge in the development of mature and functional excitable tissues is to design and construct advanced conductive biomaterials that can guide cells to form electrically interconnected networks. The objective of this study was to develop reduced graphene oxide modified silk nanofibrous biomaterials with controllable surface deposition on the nanoscale. A vacuum filtration system was applied to attain reduced graphene oxide nanolayer deposition. The results demonstrate that with this method, a uniform and compact reduced graphene oxide nanolayer was formed, and the conductivity and nanofibrous morphology of the materials was well controlled. The composite nanofibrous scaffolds were applied for the engineering of cardiac tissues and demonstrated a great ability to promote tissue formation and functions, including the expression of cardiac-specific proteins, the formation of sarcomeric structures and gap junctions, and tissue contraction. External electrical stimulation further enhanced the maturation level of cardiac tissues cultured on these conductive scaffolds. All these results demonstrated the great potential of reduced graphene oxide functionalized silk biomaterials fabricated using our method for recapitulating electrical microenvironments for the regeneration of functional excitable tissues.
\end{abstract}

\section{Introduction}

Tissue engineering has emerged as a promising approach to repair or replace the functions of diseased or damaged tissues/organs. The essential strategy of tissue engineering is to closely recapitulate the microenvironmental cues in vitro so that the regenerated tissues are sufficiently mature and functional for clinical applications $^{1-3}$. In the case of excitable tissues (e.g., cardiac and nerve tissues), the central challenge is to construct the electrical microenvironment in order to realize the

Correspondence: Feng Xu (fengxu@mail.xjtu.edu.cn) or

Xiaohui Zhang (xiaohuizhang@mail.xjtu.edu.cn)

${ }^{1}$ The Key Laboratory of Biomedical Information Engineering of Ministry of

Education, School of Life Science and Technology, Xi'an Jiaotong University, 710049 Xi'an, China

${ }^{2}$ Bioinspired Engineering and Biomechanics Center (BEBC), Xi'an Jiaotong University, 710049 Xi'an, China

Full list of author information is available at the end of the article. biomimetic transmission of electrical signals ${ }^{4-6}$. The development of advanced conductive networks has been demonstrated to be an effective approach to enhance tissue functionality during culture in vitro and avoid any symptoms due to the lack of electrical coupling with host tissues postimplantation in vivo ${ }^{7-9}$. Conductive additives, such as carbon nanotubes, gold nanowires, and polyaniline, have been incorporated by mixing into biocompatible scaffolds in the form of bulk hydrogels, microporous materials, and nanofibers to enhance scaffold conductivity ${ }^{10,11}$. However, such strategies generally require the utilization of a large amount of additives to reach their percolation threshold in order to form electrically conductive paths ${ }^{12,13}$, which may cause negative effects on the biocompatibility and mechanical properties of the scaffolds ${ }^{14,15}$. Therefore, there is a pressing demand for highly conductive additives and a suitable fabrication

\section{(c) The Author(s) 2018}

(c) (i) Open Access This article is licensed under a Creative Commons Attribution 4.0 International License, which permits use, sharing, adaptation, distribution and reproduction cc) in any medium or format, as long as you give appropriate credit to the original author(s) and the source, provide a link to the Creative Commons license, and indicate if changes were made. The images or other third party material in this article are included in the article's Creative Commons license, unless indicated otherwise in a credit line to the material. If material is not included in the article's Creative Commons license and your intended use is not permitted by statutory regulation or exceeds the permitted use, you will need to obtain permission directly from the copyright holder. To view a copy of this license, visit http://creativecommons.org/licenses/by/4.0/. 
method to construct composite biomaterials with the desired electrical conductivity while using the least amount of additives to be more favorable for the regeneration of excitable tissues.

Graphene-based nanomaterials, including graphene, graphene oxide (GO) and reduced graphene oxide (rGO), have attracted increasing attention because of their excellent conductivity ${ }^{16,17}$, making them promising candidates for fabricating highly conductive composite biomaterials in a low concentration ${ }^{18,19}$. Recent studies have also revealed that the direct absorption of GO onto biomaterials enabled the realization of high conductivity with the extremely low mass of $\mathrm{GO}^{20-22}$. In these studies, microscaled fibrous matrices $(4-170 \mu \mathrm{m})$ were employed as substrates, whose high porosities and large surface areas allowed GO platelets to fully infiltrate into pores and absorb onto fiber surfaces to form an intact and conductive GO nanolayer. However, there are several limitations in this passive absorption method. For instance, it is difficult to achieve precise control over the amount of GO that is absorbed and thus over the material conductivity. Additionally, it is difficult to further increase the material conductivity once it reaches the absorption saturation. Moreover, when the fiber diameter varies from the microscale to the nanoscale, which is more favorable for tissue regeneration, attributed to its biomimicking of structural cues, the passive absorption ability of GO was found to be significantly weakened, and resulted in a nonuniform GO layer and fibrous morphology ${ }^{23}$.

To address these challenges, we developed a simple system and accomplished the deposition of nanolayered GO onto nanofibrous biomaterials in a controllable manner. In this work, silk fibroin, which is a natural protein that has widespread biomedical applications in various formats due to its excellent biocompatibility and mechanical properties ${ }^{24}$, was selected to fabricate the nanofibrous substrates via electrospinning. GO was uniformly and tightly deposited atop silk substrates, facilitated by vacuum filtration. In addition, silk fibroin possesses excellent chemical stability, which can endure the reduction treatment of $\mathrm{rGO}$. The GO/silk composites were further reduced to $\mathrm{rGO} / \mathrm{silk}$ to enhance the conductivity and stability of the $\mathrm{rGO} /$ silk composites. This method demonstrated a great ability to fabricate GO and rGO-functionalized nanofibrous biomaterials with a wellcontrolled layer thickness, conductivity and nanofibrous morphology using isotropic or anisotropic substrates. Herein, we applied these rGO functionalized silk electrospun scaffolds for the engineering of cardiac tissues, which is a typical and intensively studied excitable tissue. The effects of the rGO coating on regulating cardiac tissue formation, morphology and functions with or without the application of external electrical stimulation were evaluated by comparing the results to those of electrospun silk controls. The synergistic effect of the scaffold conductivity and electrical stimulation was stressed to achieve a spontaneous beating capacity in the engineered cardiac tissues.

\section{Materials and methods}

Electrospun Bombyx mori silk fibroin nanofibrous scaffolds

B. mori silk fibroin solutions were prepared for electrospinning using a well-established protocol by mixing an $8 \%\left(\mathrm{w} \mathrm{w}^{-1}\right)$ silk solution with a $5 \%\left(\mathrm{w} \mathrm{v}^{-1}\right)$ poly (ethylene oxide) (PEO, 900,000 MW, Sigma-Aldrich, St. Louis, MO) solution at a value ratio of $4: 1$ and then stirring gently for $15 \mathrm{~min}$. This solution was loaded into a $10 \mathrm{~mL}$ syringe (inside diameter $\sim 1.45 \mathrm{~cm}$ ) fitted with a 12 G spinneret and was then pumped at $0.8\left(\mathrm{~mL} \mathrm{~h}^{-1}\right)$. The voltage was adjusted to $10 \mathrm{kV}$ to obtain a stable jet. For the random groups, a static platform collector (roundshaped, diameter $15 \mathrm{~cm}$ ) was used, and for the aligned groups, a high-speed rotating $(1000 \mathrm{rpm})$ disc collector (diameter $20 \mathrm{~cm}$, width $2.5 \mathrm{~cm}$ ) was used. The distance between the spinneret tip and the collector was $15 \mathrm{~cm}$, and the temperature and humidity were maintained at $30^{\circ}$ $\mathrm{C}$ and $30 \%$, respectively. The as-spun electrospun scaffolds were immersed in methanol for $15 \mathrm{~min}$ to induce a $\beta$-sheet conformational transition and were then airdried. The PEO was removed by leaching in Milli-Q water for $72 \mathrm{~h}$.

\section{$\mathrm{GO}$ vacuum filtration and reductive treatment}

GO was synthesized from natural graphite powder (diameter $<20 \mu \mathrm{m}$, Sigma-Aldrich, St. Louis, MO) by a modified version of Hummers' method ${ }^{25}$. GO solutions with a volume of $10 \mathrm{~mL}$ at concentrations of 0.01 $\left(\mathrm{mg} \mathrm{ml}^{-1}\right), 0.02\left(\mathrm{mg} \mathrm{ml}^{-1}\right), 0.04\left(\mathrm{mg} \mathrm{ml}^{-1}\right)$, and 0.08 $\left(\mathrm{mg} \mathrm{ml}^{-1}\right)$ were utilized and poured onto the electrospun silk mat fitted in the Buchner funnel of a suction flask $(5 \mathrm{~cm}$ diameter) to fabricate the $\mathrm{GO} / \mathrm{silk}$ materials, achieving GO coating densities of $\sim 0.005\left(\mathrm{mg} \mathrm{cm}^{-2}\right), 0.01$ $\left.(\mathrm{mg} \mathrm{cm})^{-2}\right), 0.02\left(\mathrm{mg} \mathrm{cm}{ }^{-2}\right)$, and $\left.0.04(\mathrm{mg} \mathrm{cm})^{-2}\right)$, respectively. After the filtration process, the composites were removed from the funnel and air-dried. For GO paper fabrication, a 10-mL GO solution at a concentration of $4\left(\mathrm{mg} \mathrm{ml}^{-1}\right)$ was vacuum filtrated through a nitrocellulose filtration membrane (diameter $6 \mathrm{~cm}$, pore size $0.22 \mu \mathrm{m}$, JINTENG, China), and air-dried after the filtration membrane was peeled off. The $\mathrm{GO} /$ silk materials and GO papers were then immersed in a $1 \%\left(\mathrm{w} \mathrm{v}^{-1}\right)$ ascorbic acid (Sigma-Aldrich, St. Louis, MO) solution at $95^{\circ} \mathrm{C}$ for $60 \mathrm{~min}$ to obtain $\mathrm{rGO} /$ silk materials and $\mathrm{rGO}$ paper. The $\mathrm{rGO} /$ silk materials and $\mathrm{rGO}$ paper were rinsed with Milli-Q water three times to remove the ascorbic acid. The randomly oriented silk and $\mathrm{rGO} /$ silk scaffolds were named silk $,(\mathrm{rGO} / \mathrm{silk})_{1-\mathrm{R}},(\mathrm{rGO} / \mathrm{silk})_{2-\mathrm{R}},\left(\mathrm{rGO} / \mathrm{silk}_{3-\mathrm{R}}\right.$, 
and $(\mathrm{rGO} / \mathrm{silk})_{4-\mathrm{R}}$, and the aligned groups were named silk $_{\mathrm{A}}, \quad(\mathrm{rGO} / \mathrm{silk})_{1-\mathrm{A}}, \quad\left(\mathrm{rGO} / \mathrm{silk}_{2-\mathrm{A}}, \quad(\mathrm{rGO} / \mathrm{silk})_{3-\mathrm{A}}\right.$, and $(\mathrm{rGO} / \text { silk })_{4-\mathrm{A}}$.

\section{Material characterizations}

Biomaterial morphologies were examined by field emission scanning electron microscopy (FSEM, Quanta 250FEG, FEI, Hillsboro, OR) after Au coating. The distributions of the fiber alignment and diameter were each obtained from measurements of 500 fibers, and the thickness of the rGO coating was obtained from measurements at 50 points. The surface topography and roughness of the materials were characterized by a $3 \mathrm{D}$ laser-measuring microscope (LEXT OLS4000, Olympus, Japan). The average roughness was calculated from measurements of 10 regions at $\times 2000$ magnification. The Raman spectra of the $\mathrm{rGO} /$ silk materials were determined using a Raman spectrometer (2208823NE, HORIBA, Japan) with a laser wavelength of $633 \mathrm{~nm}$ and a resolution of $0.47 \mathrm{~cm}$. Five locations in each group were measured to determine the average Raman spectra. The mechanical testing of the $\mathrm{rGO} /$ silk materials was conducted by using a Universal Testing Machine (criterion model 43, MTS, Eden Prairie, MN) with a $50 \mathrm{~N}$ load cell and a 10 $\left(\mathrm{mm} \mathrm{min}^{-1}\right)$ crosshead speed for wet conditions. The samples were prepared as rectangular-shaped specimens $(4 \mathrm{~mm} \times 12 \mathrm{~mm})$; at least 5 specimens from each group were tested to obtain tensile stress-strain curves. Electrical conductivity characterization was performed by a fourprobe resistance meter to measure the surface resistance of each group $(5 \mathrm{~mm} \times 10 \mathrm{~mm}$ rectangular specimens, at least three specimens from each group) before and after 10 repetitions of $20 \%$ stretching. The surface hydrophilicity/hydrophobicity was measured using a contact angle meter (SL200C1, KINO, Boston, MA) by photographing the contact angle at different times after the deposition of a $3-\mu \mathrm{L}$ water droplet.

\section{Cell culture}

Cardiomyocytes were isolated from neonatal rats using a well-established protocol. All procedures were approved by the Xi'an Jiaotong University committee on the ethical use of animals. Briefly, cardiomyocytes from neonatal rats were isolated and digested into suspended cells. After a 2 $\mathrm{h}$ differential attachment, the supernatant with suspended cardiomyocytes was combined with a 5-Br-du (SigmaAldrich, St. Louis, MO) solution at a concentration of 0.1 $\mathrm{mM}$ to inhibit the proliferation of cardiac fibroblasts. After 2 days of culture, the $\mathrm{rGO} /$ silk materials were cut into round shapes (diameter of $1 \mathrm{~cm}$ ), sterilized with $75 \%$ ethyl alcohol, and washed three times by PBS. The cardiomyocytes were seeded on $\mathrm{rGO} /$ silk materials in 48-well plates with $\sim 10^{5}$ cells in each well. 5 -Br-du was added in every exchange of the culture medium.

\section{Cell assays}

The viability of cardiomyocytes on the tested materials was evaluated using a Live/Dead Viability Kit (Invitrogen, Carlsbad, CA) and fluorescence microscopy (IX2-UCB, OLYMPUS, Japan). For F-actin staining, FITC-phalloidin (Sigma-Aldrich, St. Louis, MO) was used. For immunofluorescence staining, primary antibodies including mouse anti- $\alpha$-actinin (Abcam, Cambridge, MA), mouse anti-cTnI (Abcam, Cambridge, MA), and rabbit anti-Cx-43 (Cell Signaling Technology, Danvers, MA) were used with secondary antibodies including $488 \mathrm{~nm}$ goat anti-mouse $\operatorname{lgG}$ (Jackson, Sacramento, CA) and $594 \mathrm{~nm}$ goat anti-rabbit lgG (Jackson, Sacramento, CA). After staining the nuclei with DAPI (Thermo Scientific, Waltham, MA), images were acquired using a confocal laser-scanning microscope (FV1200, OLYMPUS, Japan). For SEM observation of cardiomyocytes, fixed $\mathrm{rGO} /$ silk materials were dehydrated using an ethyl alcohol solution and then were vacuum-dried. The cell alignment was analyzed from the staining of nucleus, which was estimated using the semiautomated "binarization-based extraction of alignment score" method, as has been described previously $^{26}$. Briefly, threshold images were analyzed using a simple optimization scheme to identify the likelihood of cells possessing a dominant axis in directions ranging from $0^{\circ}$ to $180^{\circ}$. The von Mises distributions were normalized. The nuclear aspect ratio was measured using ImageJ (1.48, NIH, Bethesda, MD) using an Orientation J plugin. The measurements of the protein expression area were determined by counting the pixels above the brightness threshold in the images using ImageJ.

\section{Real-time PCR}

An RNeasy Mini Kit (Qiagen, Germany) was used to extract the total RNA in the cultured cells following the instructions. The total concentration of RNA extracted was determined using a spectrophotometer (Nanodrop 2000, Thermo Scientific, Waltham, MA) at an optical density (OD) of $260 \mathrm{~nm}$. The reverse transcription reactions were then performed with $50 \mathrm{ng}$ of total RNA using a high capacity cDNA archive kit (Applied Biosystems, Foster City, CA) following the instructions. The customized TaqMan probe-based gene expression of the rat cardiac-specific genes $\alpha$-actinin (Actn2, Rn01470228_m1), cTnI (Tnni3, Rn00437164_m1), and Cx-43 (Gja1, Rn01433957_m1) (Thermo Scientific, Waltham, MA) and a gene expression master mix (Thermo Scientific, Waltham, MA) were used for the realtime RT-PCR reactions. These reactions were processed using an ABI 7500 Fast Sequence Detection System (Applied Biosystems, Foster City, CA). The expression level of the target genes was normalized to that of 
glyceraldehyde-3-phosphate dehydrogenase (GAPDH, Rn01775763 g1, Thermo Scientific, Waltham, MA) using the $2^{-\Delta \Delta \mathrm{Ct}}$ formula. Each sample was analyzed in triplicate.

\section{Electrical stimulation}

The designed covers for $100 \mathrm{~mm}$ Petri dishes were made from organic glass for the electrical stimulation of the samples. The covers had two parallel carbon electrodes ( $1 \mathrm{~cm}$ distance) anchored on two raised platforms on their inner surfaces. A platinum wire threaded through a hole (diameter of $1 \mathrm{~mm}$ ) in the Petri dish cover connected the carbon electrodes to an electrostimulator (Master 8, AMPI, New Ulm, MN) outside of the Petri dish. A PDMS mold with rectangular wells $(6 \mathrm{~mm} \times 18 \mathrm{~mm}$, depth $6 \mathrm{~mm})$ was produced to seed cardiomyocytes on the rectangular samples $(5 \mathrm{~mm} \times 16 \mathrm{~mm})$ for electrical stimulation. A 5-mM 1,10-dioctadecyl-3,3,30,30-tetra-methylindo-carbocyanine perchlorate (Dil, Sigma-Aldrich, St. Louis, $\mathrm{MO}$ ) solution was used to label the cardiomyocytes by incubating them at $37^{\circ} \mathrm{C}$ for $15 \mathrm{~min}$ followed by centrifugation at $800 \mathrm{rpm}$ for $5 \mathrm{~min}$. After being re-suspended in prewarmed $\left(37^{\circ} \mathrm{C}\right)$ growth medium, the cardiomyocytes were seeded onto samples with $\sim 2 \times 10^{5}$ cells in each well. After three days of culture, samples were moved to the aforementioned Petri dishes, and electrical pulses $\left(1 \mathrm{~Hz}, 5\left(\mathrm{~V} \mathrm{~cm}^{-1}\right)\right)$ were applied for 4 days by an electrostimulator. The beating of the cardiomyocytes was observed and recorded using a fluorescence microscope. The contractile rate and intensity were analyzed by comparing each video frame to those obtained during cell resting to track periodic image changes induced by cardiomyocyte beating.

\section{Statistical analysis}

The data are expressed as the mean values \pm standard deviations. Statistical comparisons were performed using one-way ANOVA and Tukey's post hoc test using OriginPro 9 (OriginLab, Northampton, MA). A significant difference is defined as ${ }^{*} p<0.05,{ }^{* *} p<0.01,{ }^{* * * *} p<0.001$.

\section{Results and discussion}

To achieve uniform coatings of GO and rGO on the surface of the silk matrices, we developed a simple vacuum filtration method. With this method, we prepared a series of $\mathrm{rGO} /$ silk hybrid conductive biomaterials with a total GO mass of $0.1-0.8 \mathrm{mg}$ using isotropic and anisotropic nanofibrous silk substrates (Supplementary Figure S1). The surface color of a silk matrix changes from white to brown upon the deposition of GO and then to black after the reduction treatment (Fig. 1a). The central and marginal regions of an rGO layer show no significant difference in the coating morphology and thickness (Fig. 1b). This uniformity of the rGO coating is also reflected by the surface color evenness of both the GO/silk and $\mathrm{rGO}$ /silk materials (Fig. 1a). The SEM images of $\mathrm{rGO} /$ silk biomaterials further confirm the uniformity of the rGO layer (Fig. 1c), regardless of the nanofiber orientations (Fig. 1d).

The thickness of the rGO layer is correlated to the GO mass (mean value of $67 \mathrm{~nm}, 105 \mathrm{~nm}, 166 \mathrm{~nm}$, and $259 \mathrm{~nm}$ for $\left(\mathrm{rGO} /\right.$ silk $_{1-\mathrm{R}},(\mathrm{rGO} / \mathrm{silk})_{2-\mathrm{R}},(\mathrm{rGO} / \mathrm{silk})_{3-\mathrm{R}}$, and $\left(\mathrm{rGO} /\right.$ silk $_{4-\mathrm{R}}$, respectively), which is independent of the nanofiber orientation (Fig. 1e). These results suggest that the rGO coating thickness can be precisely controlled. Moreover, the SEM images of the $\mathrm{rGO} /$ silk biomaterials (inserts of Fig. 1c and Supplementary Figure S2) show that the rGO is assembled in a layer-by-layer manner and tightly deposited onto the silk mats, which could be attributable to the strong suction force of the vacuum filtration.

An additional challenge is preserving the nanofibrous surface morphology of the silk mats. From the SEM images, we observed that the nanofibrous morphology of the $\mathrm{rGO} /$ silk materials gradually blurs with increasing rGO coating thickness (Fig. 1c and Supplementary Figure S2). To further study the maintenance of the nanofibrous morphology in $\mathrm{rGO} /$ silk composites, a 3D lasermeasuring microscope was employed to characterize the 3D topology and surface roughness of the scaffolds, which could indicate the quantity of the surface nanostructures. The roughness of the silk mats is measured to be $\sim 0.36 \mu \mathrm{m}$, and gradually decreases for both the random (mean value from $0.34 \mu \mathrm{m}$ to $0.22 \mu \mathrm{m}$ ) and aligned (mean value from $0.38 \mu \mathrm{m}$ to $0.21 \mu \mathrm{m}$ ) $\mathrm{rGO} /$ silk groups with increasing coating thickness (Fig. 2a-e and Supplementary Figure S3). In comparison with the $\mathrm{rGO} /$ silk materials, the rGO paper has a much lower roughness $(0.10 \pm$ $0.02 \mu \mathrm{m})$ due to the absence of surface nanostructures (Fig. 2d, e); thus, this scaffold lacks structural guidance for cell spreading and tissue organization. These results suggest the necessity of accurately controlling the thickness of the rGO layer since a thicker rGO layer will compromise the nanostructure of the underlying silk mat. Therefore, the vacuum-facilitated fabrication method enables the functionalization of a nanofibrous silk matrix with an rGO nanocoating while maintaining the matrix morphology and demonstrates superior ability in controlling the uniformity and thickness of the GO and rGO coatings to that of passive GO absorption methods ${ }^{23}$.

Raman spectrometry was utilized to examine the existence of rGO layers. The characteristic band of the $\beta$-sheet at $\sim 1670 \mathrm{~cm}^{-1}$ (amide I) is clearly observed for the silk mat (Fig. 2f). The characteristic silk bands completely disappear after rGO coating, suggesting that an intact rGO layer is coated on the surface of the silk mats. In the Raman spectra of the $\mathrm{rGO} /$ silk composites, the bands at $\sim 1320 \mathrm{~cm}^{-1}$ and $1580 \mathrm{~cm}^{-1}$ correspond to the 


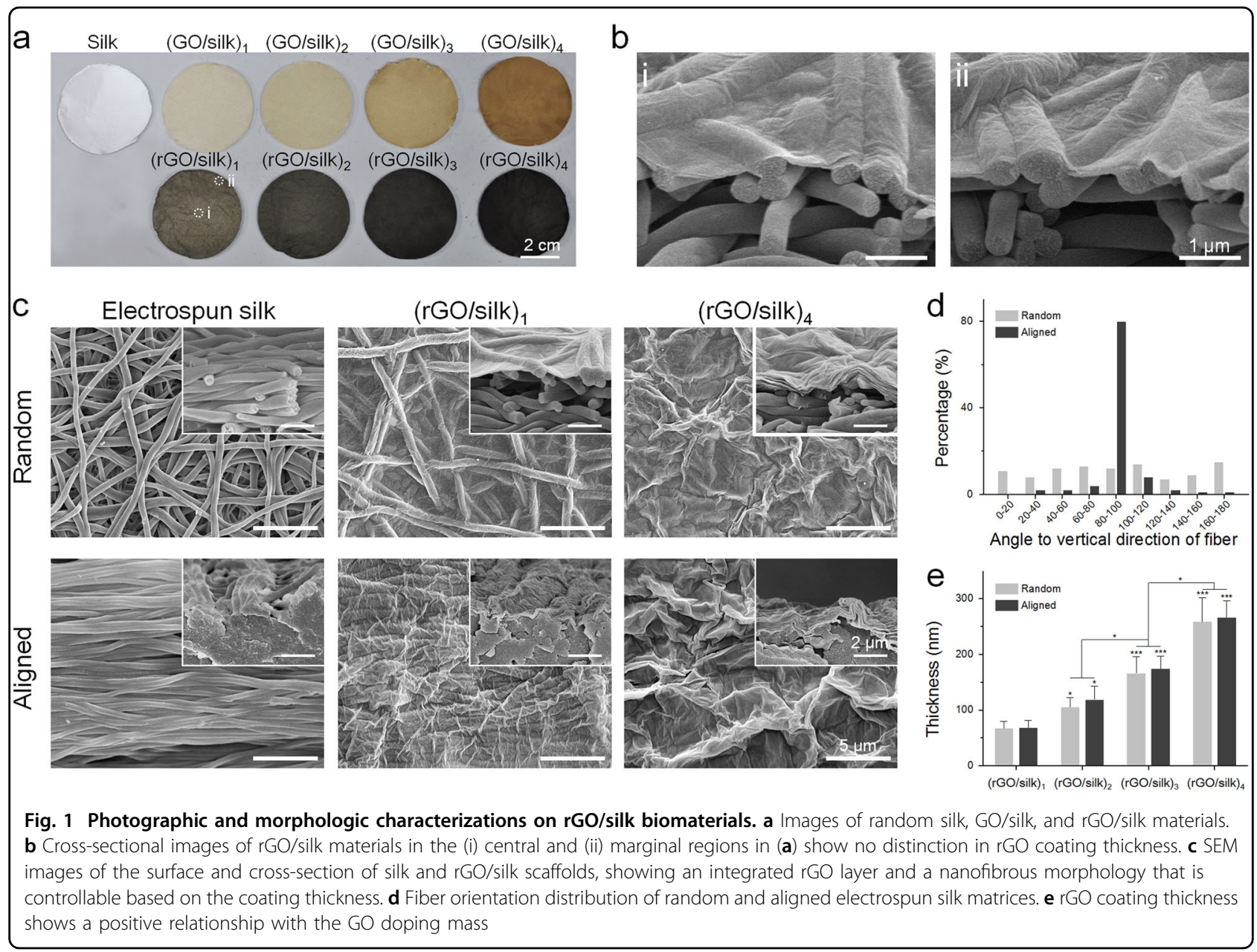

$\mathrm{D}$ and $\mathrm{G}$ modes of $\mathrm{rGO}$, respectively. We observed that the intensity ratio of the $D$ band to the $G$ band is significantly higher for all the $\mathrm{rGO} /$ silk materials (1.43-1.66, Fig. 2f) than for the GO paper (0.88, Supplementary Figure S4), indicating the reduction of the rGO layer ${ }^{27}$. Moreover, the increased rGO band intensity is correlated to the increase in the rGO coating thickness.

The excellent conductivity of rGO/silk endowed by an rGO coating was further confirmed by a light-emitting diode (LED) reflection assay, as the two groups with thinner rGO coatings can light the LED with varying luminosities (Fig. 2g). The conductivity of the random $\mathrm{rGO} /$ silk composites increases with increasing $\mathrm{rGO}$ coating thickness (mean resistance of $4866.7 \mathrm{M} \Omega$, 80.7 M $\Omega, 12.6 \mathrm{M} \Omega$, and $4.3 \mathrm{M} \Omega$ for $(\mathrm{rGO} / \text { silk })_{1-\mathrm{R}}$, $(\mathrm{rGO} /$ silk $)_{2-\mathrm{R}}, \quad(\mathrm{rGO} / \mathrm{silk})_{3-\mathrm{R}}$, and $(\mathrm{rGO} / \text { silk })_{4-\mathrm{R}}$, respectively) (Fig. 2h). In the aligned $\mathrm{rGO} /$ silk groups, we observed an anisotropy of conductivity (Fig. 2h), where the resistance measured from the direction parallel to the nanofiber orientation is significantly lower than that measured from the vertical direction. This anisotropy may be attributed to the difference in the conductor length (longer in the vertical direction than the parallel direction) and the cross-sectional area (smaller in the vertical direction than the parallel direction) of the rGO layer deposited on the aligned silk mats (Supplementary Figure S5). This anisotropic conductivity of the aligned $\mathrm{rGO} /$ silk scaffolds could lead to a stronger transmission of electrical signals along the orientation of the aligned nanofibers and cultured tissues, which biologically mimics the directional electrical transmission in native excitable tissues.

As excitation-contraction coupling tissues may possess contraction-induced strain (e.g., myocardium and skeletal muscle), we further studied the conductivity of the $\mathrm{rGO} /$ silk scaffolds and integrity of rGO after repeated stretching. After 10 cycles of stretching at $20 \%$, the resistance increases by 281,529 and $637 \%$ for $(\mathrm{rGO} / \mathrm{silk})_{1}$. $\mathrm{R},(\mathrm{rGO} / \mathrm{silk})_{2-\mathrm{R}}$, and $(\mathrm{rGO} / \text { silk })_{3-\mathrm{R}}$, respectively; $(\mathrm{rGO} /$ silk) $)_{4-\mathrm{R}}$ becomes an insulator (Fig. $2 \mathrm{i}$ ). The increase in the resistance of the $\mathrm{rGO} /$ silk scaffolds is associated with the fracturing of the rGO layer caused by stretching, as confirmed by the integrity of the rGO coating before and after 20\% stretching (Fig. 2j and Supplementary Figure S6). Thinner rGO layers tend to elongate evenly 


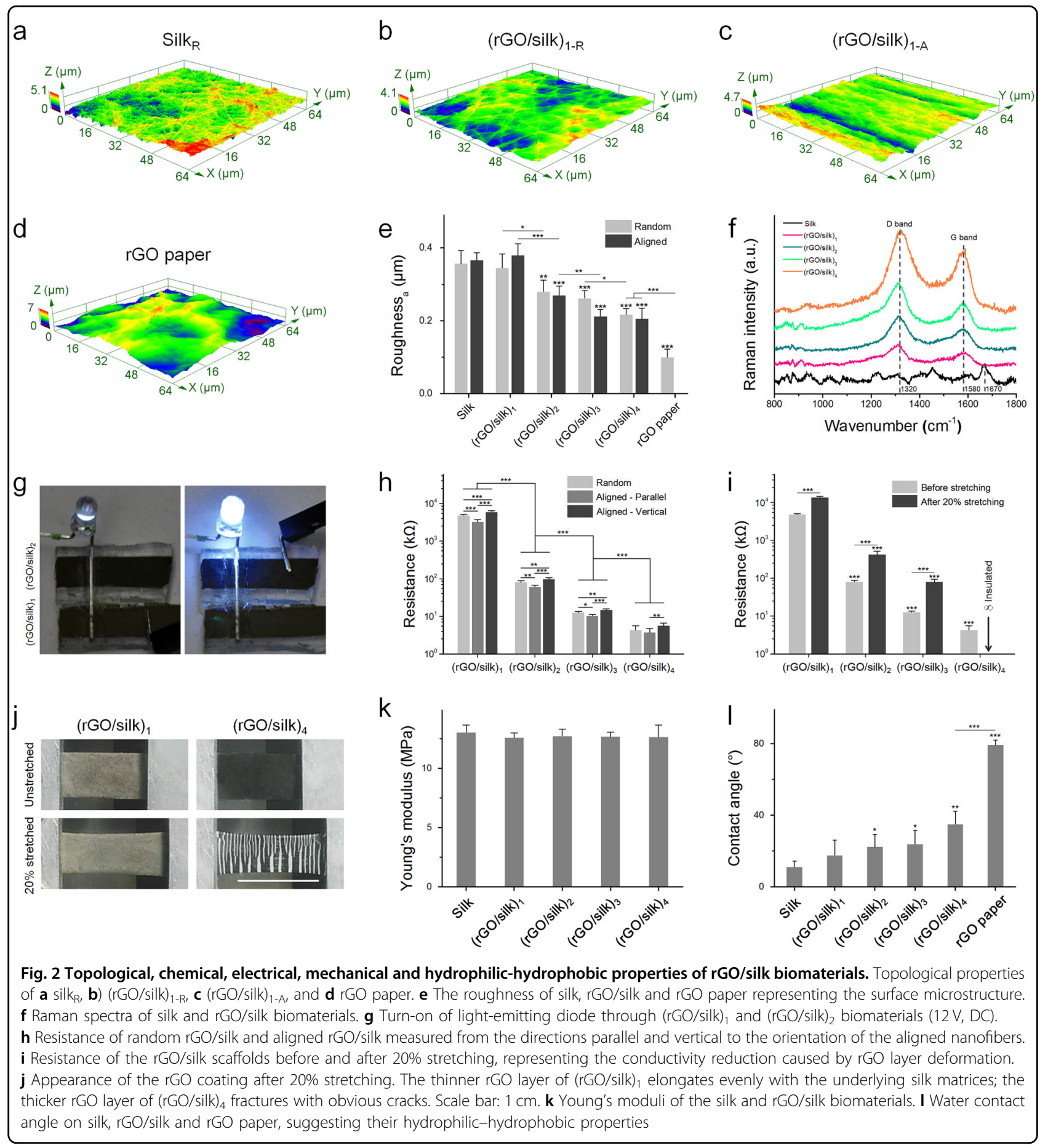

with the underlying silk matrices, demonstrating strong interface adhesion between the rGO layer and the silk matrices, which could be due to the formation of hydrogen bonds ${ }^{28}$. However, thicker rGO layers fracture with evident cracks, which are wider and more fatal to the interconnection of the whole rGO layer with increasing rGO thickness. This result is as expected from the Weibull scaling of strength for brittle materials ${ }^{29}$, with thicker coatings more likely to possess a critical-size defect. These results demonstrate that the $\mathrm{rGO}$ layer in the $\mathrm{rGO} /$ silk scaffolds is more resistant to strain-induced fracture with thinner coatings and thus is more likely to maintain its structural integrity and conductivity, suggesting that these composites are favorable for applications in flexible electronics and the engineering of excitation-contraction coupling tissues (e.g., myocardium and skeletal muscle). 
We further investigated the influence of GO coatings and the reductive treatment on the mechanical properties of $\mathrm{rGO} /$ silk composites. No significant change in the tensile Young's modulus after rGO coating is found in any of the study groups (Fig. 2k), as expected, due to the relatively low volume fraction of $\mathrm{rGO}$ and the stability of silk fibroin in reduction treatment.

The hydrophobicity of rGO paper $\left(79.3 \pm 2.5^{\circ}\right.$, Fig. 2l) makes this scaffold unfavorable for cell adhesion and spreading ${ }^{30}$. The combination of silk substrates with an rGO nanolayer significantly increases the hydrophilicity of the composites (from $35.0 \pm 7.1^{\circ}$ to $17.6 \pm 8.5^{\circ}$ ), where the hydrophilicity of $\mathrm{rGO} / \mathrm{silk}$ increases with a reduction in the rGO thickness (Fig. 2l). This effect could be attributed to the excellent hydrophilicity $\left(11.1 \pm 3.1^{\circ}\right)$ and surface nanostructure of electrospun silk mats underlying the rGO layer.

The superior electrical conduction properties of the rGO coating were achieved with a trace amount of conductive additives ( $\mathrm{rGO}$ layer reduced from a minimum of $0.005 \mathrm{mg}$ GO per $\mathrm{cm}^{2}$ ), which influenced the other material properties only slightly. The excellent controllability of this fabrication method enables precise control over the coating thickness, nanofibrous morphology and conductivity, and the development of composites that have potential applications in biomedicine and other fields. Moreover, this method could allow the deposition of GO and rGO nanolayers on aligned nanofibrous scaffolds while maintaining the anisotropic surface morphology, which is favorable for engineering some excitable tissues that require structural guidance to form ordered and biomimicking tissues (e.g., cardiac and nerve tissues).

To investigate the potential of conductive $\mathrm{rGO} / \mathrm{silk}$ materials for engineering excitable tissues, we chose cardiac tissues, one of the most widely studied excitable tissues that could be functionally improved by a conductive scaffold and electrical stimulation, as the test model in our cell experiment. Cardiomyocytes isolated from neonatal rats were seeded and cultured on the scaffolds and assessed on days 1, 4, and 7. Cardiomyocytes cultured on silk, rGO/silk composites and rGO paper all demonstrate a high viability during the 7 days of culture (Fig. 3a, b and Supplementary Figure S7). This result suggests an excellent biocompatibility of rGO for cardiomyocyte culture.

The $\mathrm{rGO} /$ silk composite demonstrated an enhanced ability to promote the organization of cardiac tissues. From F-actin staining, we observed that cardiomyocytes cultured on $(\mathrm{rGO} / \mathrm{silk})_{1},(\mathrm{rGO} / \mathrm{silk})_{2}$, and $(\mathrm{rGO} / \mathrm{silk})_{3}$ exhibit more striated and mature cytoskeleton structures and larger spreading areas than those cultured on bare silk scaffolds (Fig. 3c and Supplementary Figure S8). These differences might be due to the abundant functional groups on the rGO layers as well as to the improved conductivity $^{31}$. This effect becomes less significant on thicker rGO coatings that are sufficiently thick to make the surface of the $\mathrm{rGO} /$ silk composites smoother, especially those in the $\left(\mathrm{rGO} /\right.$ silk $_{4}$ group, indicating a critical role of topological cues in regulating cardiomyocyte morphology ${ }^{32}$. Moreover, cardiomyocytes cultured on $(\mathrm{rGO} / \text { silk })_{1-\mathrm{A}},(\mathrm{rGO} / \mathrm{silk})_{2-\mathrm{A}}$, and $(\mathrm{rGO} / \text { silk })_{3-\mathrm{A}}$ spread into rod shapes and oriented along the fiber direction (Fig. 3c, d and Supplementary Figure S8). The cell alignment is less significant with the increase in the rGO layer thickness and the associated loss of structural cues (Fig. 3d). The effect of topographical cues in the rGO/silk scaffolds on cardiomyocytes could also be observed in the SEM images, where the cardiomyocytes are extended with a spindle-shaped appearance along the nanofiber alignment of the silk and $\mathrm{rGO} /$ silk scaffolds for the thin layer thickness (Fig. 3e and Supplementary Figure S9). Quantitative analyses of the nuclear aspect ratio (Fig. 3f) and alignment score (Fig. 3g) further confirm these observations, suggesting the importance of precisely controlling the rGO thickness to avoid compromising the positive effects of the scaffold conductivity and topographical cues.

To assess the effect of the rGO layer on the maturation of cardiac tissues, we analyzed the expression of cardiacspecific proteins including $\alpha$-actinin, cTnI and $\mathrm{Cx}-43$ after 7 days of culture using immunofluorescence. Similar to the results of F-actin staining, the immunofluorescence results showed that the expression of $\alpha$-actinin is significantly promoted by a thinner rGO layer relative to the unmodified silk scaffolds $\left(109 \pm 5 \mu \mathrm{m}^{2}, 151 \pm 11 \mu \mathrm{m}^{2}\right.$, and $160 \pm 7 \mu \mathrm{m}^{2}$ per cell in the silk $\mathrm{R}_{\mathrm{R}},(\mathrm{rGO} / \text { silk })_{1-\mathrm{R}}$ and $(\mathrm{rGO} /$ silk) $)_{2-\mathrm{R}}$ groups, respectively; $99 \pm 10 \mu \mathrm{m}^{2}, 175 \pm 5 \mu \mathrm{m}^{2}$, and $191 \pm 15 \mu \mathrm{m}^{2}$ per cell in the silk $\mathrm{A}_{\mathrm{A}},(\mathrm{rGO} / \mathrm{silk})_{1-\mathrm{A}}$ and (rGO/silk) $)_{2-\mathrm{A}}$ groups, respectively). However, this effect diminishes with the increase in the rGO layer thickness $\left(147 \pm 10 \mu \mathrm{m}^{2}\right.$ and $119 \pm 12 \mu \mathrm{m}^{2}$ per cell in the (rGO/ silk) ${ }_{3-\mathrm{R}}$ and $(\mathrm{rGO} / \text { silk) })_{4-\mathrm{R}}$ groups, respectively; $164 \pm 15$ $\mu \mathrm{m}^{2}$ and $143 \pm 12 \mu \mathrm{m}^{2}$ per cell in the (rGO/silk) $3-\mathrm{A}$ and $(\mathrm{rGO} / \text { silk })_{4-\mathrm{A}}$ groups, respectively) (Fig. $\left.4 \mathrm{a}, \mathrm{c}\right)$. These results suggest that the rGO layers and nanofibrous topographical cues have synergistic effects on the maturation of cardiac tissues. As evident from the localization of $\alpha$-actinin at the Z-line, sarcomeric structures are observed in cardiomyocytes cultured on all the studied scaffolds (Fig. 4a). Moreover, we found that the width of the sarcomeres, which represents the contractile ability of cardiomyocytes, is maximized by the synergistic effect of the $\mathrm{rGO}$ layer and nanofibrous structure of the $(\mathrm{rGO} / \text { silk })_{2}$ group $\left(1.7 \pm 0.3 \mu \mathrm{m}\right.$ for $(\mathrm{rGO} / \text { silk })_{2-\mathrm{R}}$ compared to $1.0 \pm 0.2 \mu \mathrm{m}$ for silk $k_{R}$ and $1.6 \pm 0.4 \mu \mathrm{m}$ for (rGO/silk) 2 -A compared to $0.7 \pm 0.1 \mu \mathrm{m}$ for silk $\mathrm{A}_{\mathrm{A}}$ ) (Fig. $4 \mathrm{~d}$ ). Based on the aforementioned results, including the resistance to strain (Fig. 2), guidance for oriented tissue formation (Fig. 3), and promotion of sarcomere formation 


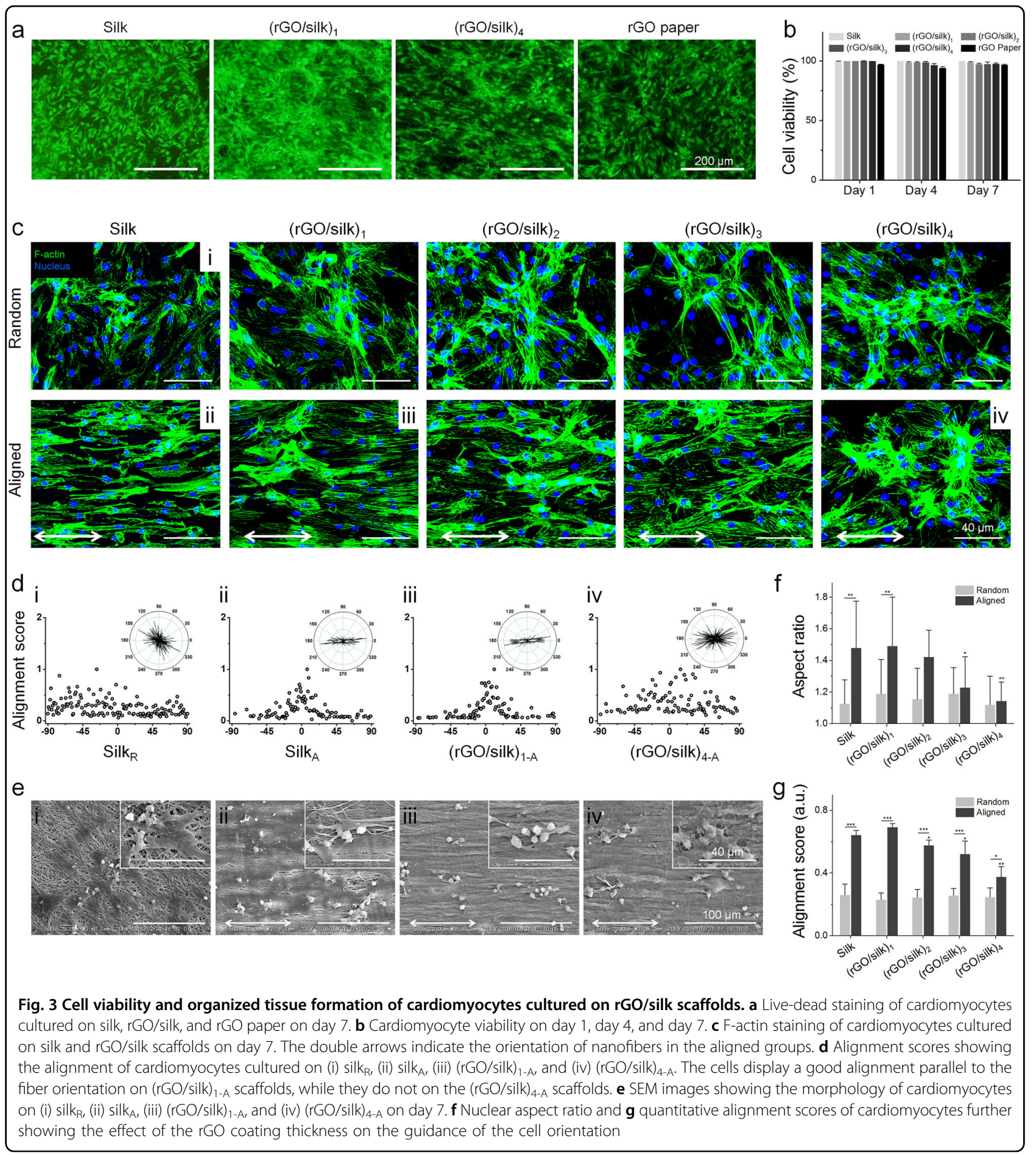

(Fig. 5), (rGO/silk) $)_{1}$ and (rGO/silk) $)_{2}$ were found to be superior to $(\mathrm{rGO} / \text { silk })_{3}$ and $(\mathrm{rGO} / \text { silk })_{4}$; thus we selected these two groups for further characterization of their performance for engineering functional cardiac tissues.

cTnI, which could label the sarcomeric $\beta$-myosin heavy chain, was costained with $\alpha$-actinin to further confirm the sarcomere structures (Fig. $4 \mathrm{~b}$ and Supplementary
Figure S10). The expression of cTnI exhibits a complementary distribution to that of $\alpha$-actinin (Fig. 4b), which is coincident to the localization of the $\beta$-myosin heavy chain and Z-line in sarcomeres. The quantitative analysis revealed that the expression of cTnI is significantly improved in $\left(\mathrm{rGO} /\right.$ silk $_{1-\mathrm{A}},\left(\mathrm{rGO} / \mathrm{silk}_{2-\mathrm{A}}\right.$, and $(\mathrm{rGO} / \text { silk })_{2-\mathrm{R}}$ scaffolds compared to that in bare silk 


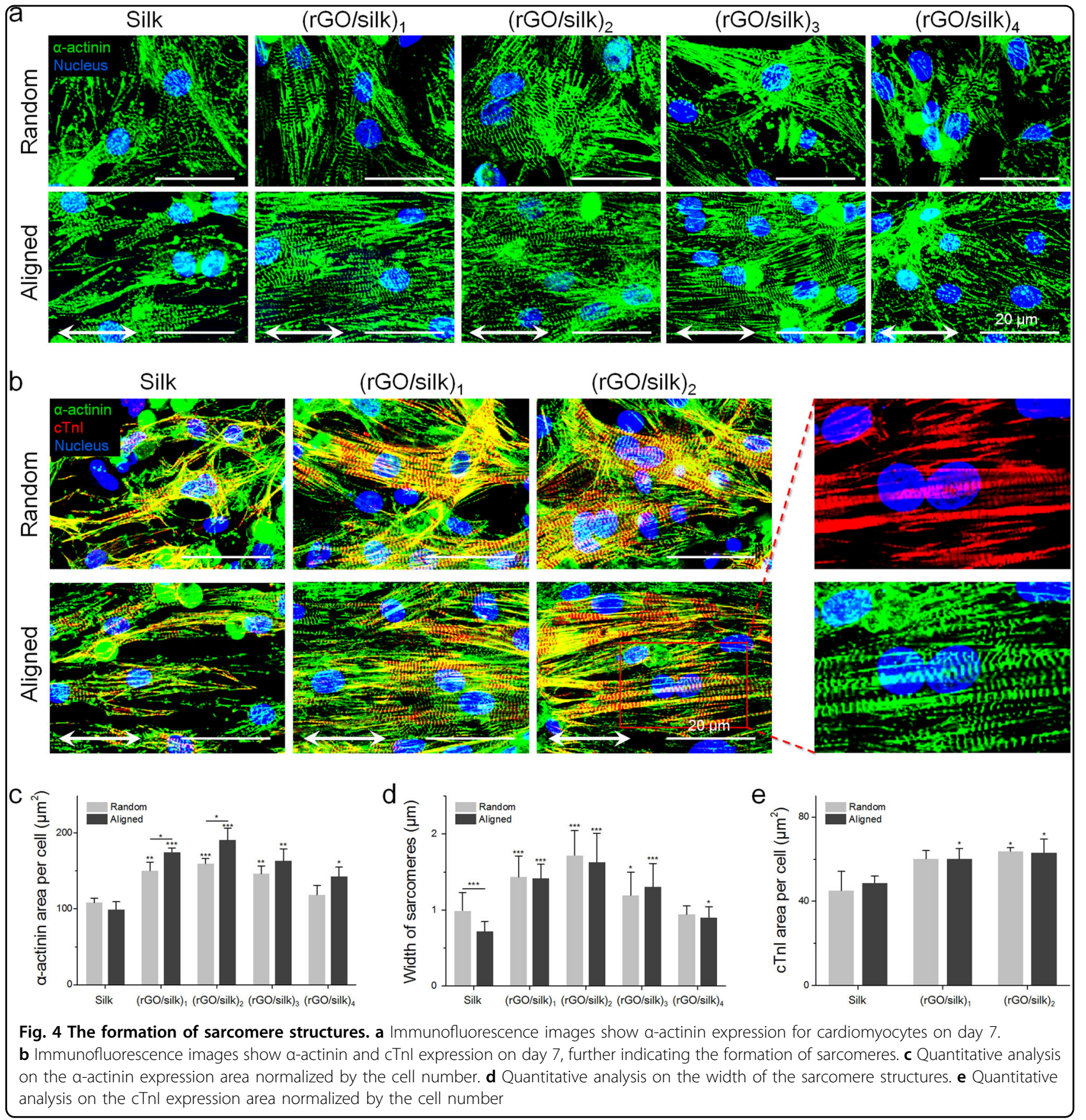

scaffolds (Fig. 4e). From these results, we confirm that the synergy of the conductivity and aligned nanofibrous topographical cues is ideal to enhance the expression of sarcomeric proteins and improve the formation of aligned and strengthened sarcomeric structures ${ }^{33}$. The optimal thickness of the $\mathrm{rGO} /$ silk coating is a tradeoff between the enhanced conductivity of thicker rGO coatings and the well-maintained nanofibrous cues of thinner rGO coatings.
To assess the electrical coupling and communication of regenerated cardiac tissues, $\mathrm{Cx}-43$ was costained with $\alpha$-actinin to examine the formation of gap junctions. We observed that $\mathrm{Cx}-43$ expression is significantly higher in cardiomyocytes cultured on $(\mathrm{rGO} /$ silk) $)_{1}$ and $(\mathrm{rGO} / \mathrm{silk})_{2}$ for 7 days than in those cultured on silk fibroin scaffolds (Fig. 5a-c and Supplementary Figure S11). Moreover, Cx-43 expression is enriched at the boundary of adjacent cardiomyocytes, especially 


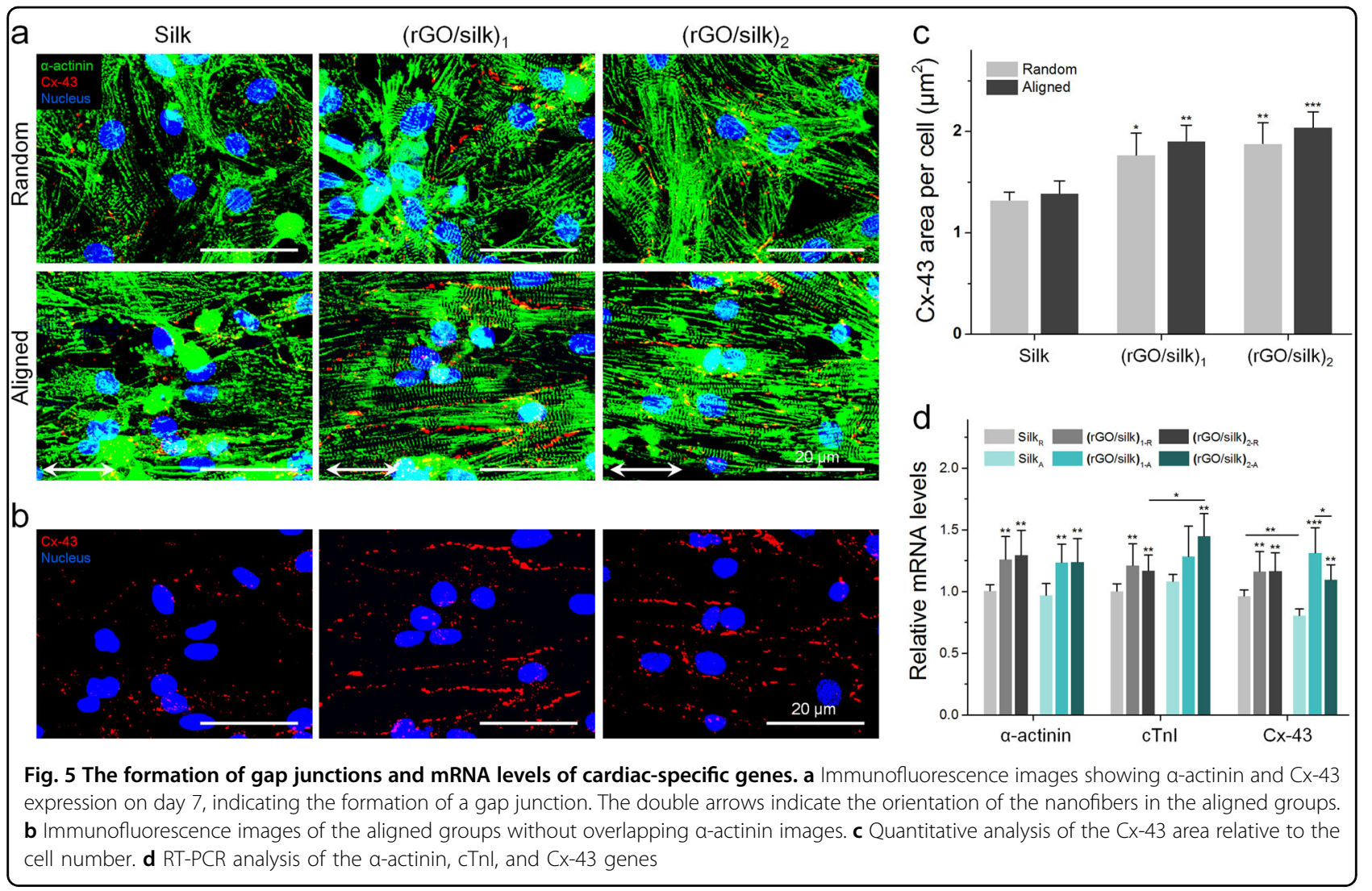

those cultured on the aligned $\mathrm{rGO} /$ silk scaffolds. These results indicate the capability of $\mathrm{rGO} /$ silk scaffolds to enhance cell-cell communication, which is an important symbol for the functionalization of cardiac tissues ${ }^{34}$.

The expression of $\alpha$-actinin, cTnI, and $\mathrm{Cx}-43$ was also examined at the mRNA level (Fig. 5d). Significant upregulation of all the markers is observed in cardiomyocytes cultured on $(\mathrm{rGO} / \text { silk })_{2}$ scaffolds compared to the marker expression in bare silk scaffolds. However, there is no significant difference in the transcript expression levels in cardiomyocytes cultured on aligned and random $\mathrm{rGO} /$ silk scaffolds. These results suggest that nanofiber alignment is more effective for the organization of proteins than gene transcription and protein expression. Therefore, $(\mathrm{rGO} / \mathrm{silk})_{2}$ scaffolds were selected to study the effects of electrical stimulation on the further improvement of cardiac functions.

To investigate the effect of electrical stimulation on cardiac tissue functions, we applied electrical stimulation to cardiomyocytes 3 days after seeding using a custommade Petri dish cover $(100 \mathrm{~mm})$ that provides parallel electric fields to the cells (Fig. 6a). A parallel-pulsed electric field $\left(1 \mathrm{~Hz}, 5\left(\mathrm{~V} \mathrm{~cm}^{-1}\right)\right)$ was employed, and the electrical stimulation was maintained for 4 days during culture.
The expression of cTnI and $\mathrm{Cx}-43$ were enhanced by the electrical stimulation of the cardiac tissues on rGO/silk scaffolds (Fig. 6b and Supplementary Figures 10-11. The tissues, especially those on the aligned $\mathrm{rGO} /$ silk scaffolds, exhibit elongated and interconnected sarcomeric structures with uniaxial alignment along the silk nanofibrous orientation with electrical stimulation. The quantitative analysis of the expression area of cTnI and Cx-43 revealed that electrical stimulation significantly increases the expression of cTnI and $\mathrm{Cx}-43$ on the aligned $\mathrm{rGO}$ /silk scaffolds by $\sim 1.5$ and 2.1 times those on aligned silk scaffolds, respectively (Fig. $6 \mathrm{c}-\mathrm{d}$ ). However, for cardiac tissues on random silk and $\mathrm{rGO} /$ silk scaffolds, the $\mathrm{Cx}-43$ expression level shows no significant change after electrical stimulation, suggesting that coupling between the direction of electrical stimulation and the tissue orientation is essential for the enhancement of cell-cell coupling. We also observed that in the aligned silk group, the $\mathrm{Cx}-43$ expression level is significantly reduced in the groups with electrical stimulation (Fig. 6d).

The spontaneous beating of engineered cardiac tissues with or without electrical stimulation was examined and recorded to further characterize the tissue electrophysiology (Fig. 6e-g). We observed a spontaneous 


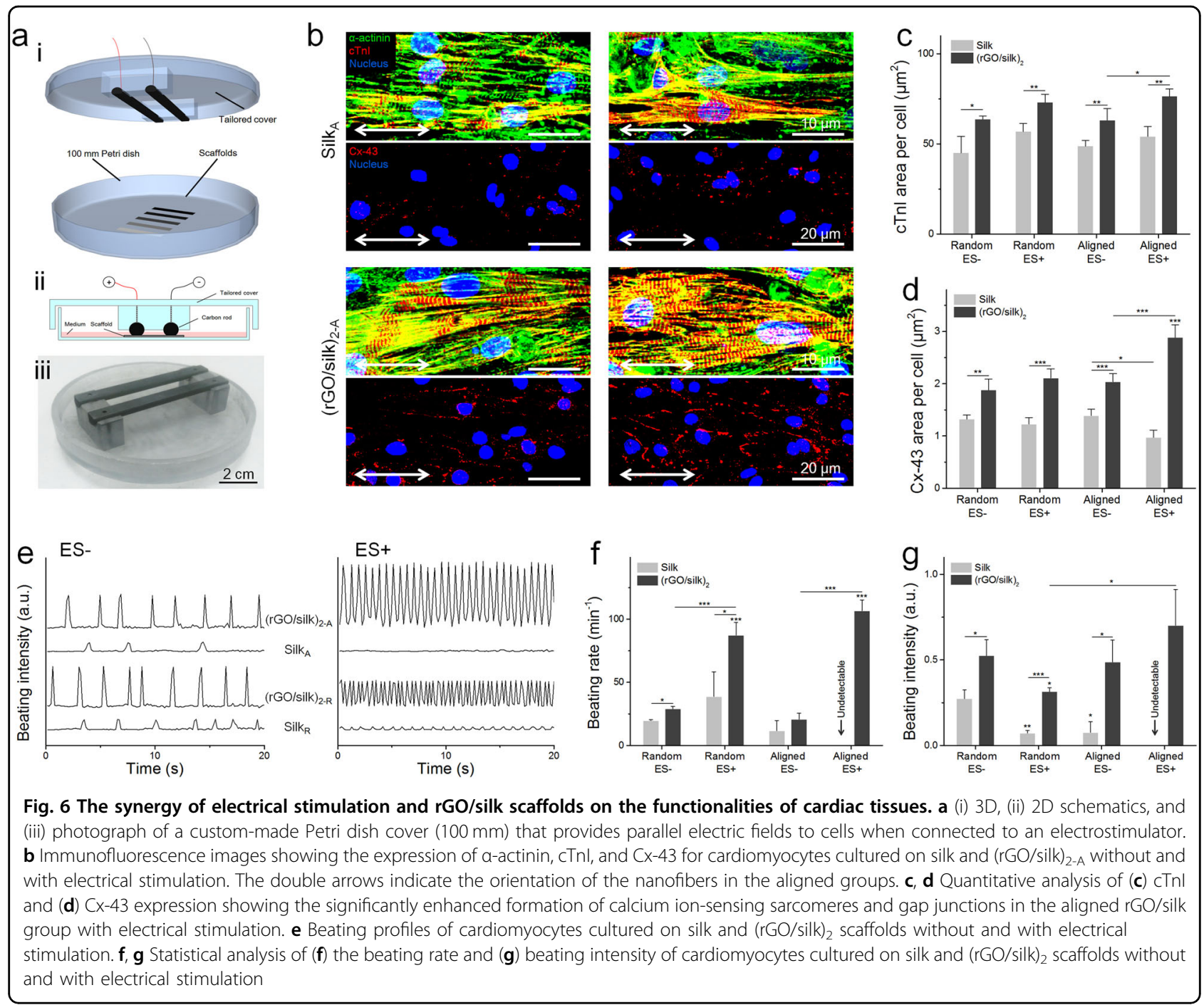

beating ability of cardiac tissues in all groups without electrical stimulation. The beating rate and intensity of cardiac tissues on $\mathrm{rGO} /$ silk scaffolds are significantly higher than those of cardiac tissues on silk scaffolds. This result is consistent with the enhanced expression of cardiac-specific proteins in tissues on $\mathrm{rGO}$ /silk scaffolds. Therefore, the incorporation of an rGO nanolayer can enhance the electrophysiological function of cardiac tissues relative to the effect of bare silk scaffolds even without electrical stimulation.

We found that the beating of cardiac tissues engineered on $\mathrm{rGO} /$ silk scaffolds can be further improved by electrical stimulation. However, this effect is not observed for the cardiac tissues engineered on bare silk scaffolds (Fig. 6e). Cardiac tissues on rGO/silk scaffolds exhibit stable and enhanced spontaneous synchronous beating with an increased beating rate and intensity upon the removal of electrical stimulation (Fig. 6e). Quantitative analyses reveal that electrical stimulation significantly accelerates the beating rate of tissues on random $\mathrm{rGO} /$ silk scaffolds (from $29.1 \pm 1.8 \mathrm{~min}^{-1}$ to $87.4 \pm 10.0 \mathrm{~min}^{-1}$ ) and aligned $\mathrm{rGO} /$ silk scaffolds (from $20.8 \pm 4.6 \mathrm{~min}^{-1}$ to $106.5 \pm 8.8 \mathrm{~min}^{-1}$ ) (Fig. 6f) and enhances the contractile intensity of tissues on aligned $\mathrm{rGO} /$ silk scaffolds (relative value from $0.49 \pm 0.13$ to $0.70 \pm 0.21$ ) (Fig. 6g). Collectively, rGO coatings, electrical stimulation, and aligned morphology worked synergistically (aligned $\mathrm{rGO} / \mathrm{silk}$ scaffolds with electrical stimulation) to improve the contractile rate to 5.4 times (mean value of $106.5 \mathrm{~min}^{-1}$ compared to $19.7 \mathrm{~min}^{-1}$ ) and the contractile intensity to 2.6 times (mean value of 0.70 compared to 0.27 ) that of the tissues on the random silk scaffolds without electrical stimulation.

After electrical stimulation, the spontaneous beating of cardiac tissues on random silk scaffolds weakened and that on aligned silk scaffolds became undetectable. This result is consistent with the reduced $\mathrm{Cx}-43$ expression level observed in the aligned silk group after electrical 
stimulation. This effect may be attributed to the lower spreading area of cardiomyocytes on silk scaffolds and their rod-shaped morphology on aligned scaffolds (Fig. 3c). These two factors work together and result in cardiomyocytes being less likely to contact adjacent cells than those on rGO-coated scaffolds at the same cell density. Thus, the opportunity to form gap junctions between cardiomyocytes on aligned silk scaffolds was significantly reduced. This hypothesis was supported by another study that suggested that $\mathrm{Cx}-43$ is highly expressed in grouped cells rather in single separated cells $^{35}$. Thus, the cardiac tissues in the aligned silk group exhibited the weakest cell-cell communication and could have had a lower tolerance to electrical stimulation than those on random silk or $\mathrm{rGO} /$ silk scaffolds, leading to a negative influence on $\mathrm{Cx}-43$ expression and the beating function after electrical stimulation (Fig. 6e-g).

The synergistic effects of a conductive rGO nanolayer, an aligned nanofibrous morphology and external electrical stimulation improved the function of engineered cardiac tissues. The incorporation of a conductive rGO layer allowed pacemaker cells to transmit electrical signals to cardiomyocytes at a distance in addition to adjacent cells and to form electrical coupling with other pacemaker cells ${ }^{10,36}$, promoting cell cluster confluence and synchronized beating ${ }^{37}$. Electrical signals transmitted much more effectively through rGO layers than through cell culture medium, perhaps resulting in a promotion of gap junction formation among electrically coupled cardiomyocytes ${ }^{38,39}$, which is a key factor in enabling electrical communication between implanted tissues and the native myocardium ${ }^{7,40}$. Aligned and well-organized cardiac tissues grown on aligned $\mathrm{rGO} /$ silk matrices exhibited an improved formation of cell-cell gap junctions and strengthened beating function. These three factors worked synergistically to promote cell-cell communication. Aligned $\mathrm{rGO} /$ silk scaffolds with an rGO coating thickness of $\sim 100$ $\mathrm{nm}$ are the most effective in this regard.

\section{Conclusion}

In summary, we successfully fabricated rGOfunctionalized nanofibrous silk fibroin materials and demonstrated their potential for regenerating functional excitable tissues. This method can deposit a uniform rGO layer upon both isotropic and anisotropic nanofibrous substrates and precisely control the layer thickness on the nanoscale. With ultrathin coatings, the $\mathrm{rGO} /$ silk materials exhibited a high conductivity while maintaining the topological cues and flexibility of nanofibrous matrices. For engineering excitable tissues, the $\mathrm{rGO} /$ silk matrices promoted cell spreading, cardiac-specific protein expression, the formation of sarcomeric structure and cell-cell gap junctions, and spontaneous beating of regenerated cardiac tissues. Moreover, the rGO layer enhanced the promotive effect of electrical stimulation on cardiac tissues. Overall, the rGO nanolayer-coated nanofibrous biomaterials demonstrate promise in cardiac tissue engineering applications and the potential to be extended for regenerating other excitable tissues and developed for electrical applications such as flexible electronics and sensors.

\begin{abstract}
Acknowledgements
This work was financially supported by the National Key Research and Development Program of China (2018YFC1002802), the National Natural Science Foundation of China (81401270, 11522219, 11532009), the International Cooperation and Exchange of the National Natural Science Foundation of China (11761161004), the China Young 1000-Talent Program award granted to X.H. Zhang, the National Institutes of Health under grant R01HL109505, and the NSF Science and Technology Center for Engineering MechanoBiology (CMMI 1548571).
\end{abstract}

\section{Author details}

'The Key Laboratory of Biomedical Information Engineering of Ministry of Education, School of Life Science and Technology, Xi'an Jiaotong University, 710049 Xi'an, China. ${ }^{2}$ Bioinspired Engineering and Biomechanics Center (BEBC), Xi'an Jiaotong University, 710049 Xi'an, China. ${ }^{3}$ State Key Laboratory for Mechanical Behavior of Materials, Xi'an Jiaotong University, 710049 Xi'an, China. ${ }^{4}$ NSF Science and Technology Center for Engineering Mechanobiology, Washington University in St. Louis, St. Louis 63130 MO, USA. ${ }^{5}$ MOE Key Laboratory for Multifunctional Materials and Structures, Xi'an Jiaotong University, 710049 Xi'an, China. ${ }^{6}$ State Key Laboratory of Mechanics and Control of Mechanical Structures, Nanjing University of Aeronautics and Astronautics, 210016 Nanjing, China. ${ }^{7}$ Department of Chemical and Biomolecular Engineering, Hong Kong University of Science and Technology, Clear Water Bay, Hong Kong

\section{Conflict of interest}

The authors declare that they have no conflict of interest.

\section{Publisher's note}

Springer Nature remains neutral with regard to jurisdictional claims in published maps and institutional affiliations.

Supplementary information is available for this paper at https://doi.org/ 10.1038/s41427-018-0092-8.

Received: 15 June 2018 Revised: 15 August 2018 Accepted: 22 August 2018.

Published online: 11 October 2018

\section{References}

1. Dhahri, W., Romagnuolo, R. \& Laflamme, M. A. Training heart tissue to mature. Nat. Biomed. Eng. 2, 351-352 (2018).

2. Dvir, T., Timko, B. P., Kohane, D. S. \& Langer, R. Nanotechnological strategies for engineering complex tissues. Nat. Nanotech. 6, 13 (2010).

3. Li, Y. et al. Magnetically actuated cell-laden microscale hydrogels for probing strain-induced cell responses in three dimensions. NPG Asia Mater. 8, e238 (2016).

4. Dvir, T. et al. Nanowired three-dimensional cardiac patches. Nat. Nanotech. 6 , 720-725 (2011).

5. Elson, E. L. \& Genin, G. M. Tissue constructs: platforms for basic research and drug discovery. Interface Focus 6, 20150095 (2016).

6. Feiner, R. et al. Engineered hybrid cardiac patches with multifunctional electronics for online monitoring and regulation of tissue function. Nat. Mater. 15, 679 (2016).

7. Leobon, B. et al. Myoblasts transplanted into rat infarcted myocardium are functionally isolated from their host. Proc. Natl Acad. Sci. USA 100, 7808-7811 (2003).

8. Zhao, G., Zhang, X., Lu, T. J. \& Xu, F. Recent advances in electrospun nanofibrous scaffolds for cardiac tissue engineering. Adv. Funct. Mater. 25, 5726-5738 (2015) 
9. Feiner, R. \& Dvir, T. Tissue-electronics interfaces: from implantable devices to engineered tissues. Nat. Rev. Mater. 3, 17076 (2018).

10. Shin, S. et al. Carbon-nanotube-embedded hydrogel sheets for engineering cardiac constructs and bioactuators. ACS Nano 7, 2369-2380 (2013).

11. Hsiao, C. et al. Electrical coupling of isolated cardiomyocyte clusters grown on aligned conductive nanofibrous meshes for their synchronized beating. Biomaterials 34, 1063-1072 (2013).

12. Borriello, A., Guarino, V., Schiavo, L., Alvarez-Perez, M. A. \& Ambrosio, L. Optimizing PANi doped electroactive substrates as patches for the regeneration of cardiac muscle. J. Mater. Sci. Mater. Med. 22, 1053-1062 (2011).

13. McCullen, S. et al. Morphological, electrical, and mechanical characterization of electrospun nanofiber mats containing multiwalled carbon nanotubes. Macromolecules 40, 997-1003 (2007).

14. Smart, S. K., Cassady, A. I., Lu, G. Q. \& Martin, D. J. The biocompatibility of carbon nanotubes. Carbon 44, 1034-1047 (2006).

15. Pan, $H$. et al. Significantly reinforced composite fibers electrospun from silk fibroin/carbon nanotube aqueous solutions. Biomacromolecules 13, 2859 (2012).

16. Loh, K. P., Bao, Q., Ang, P. K. \& Yang, J. The chemistry of graphene. J. Mater. Chem. 20, 2277-2289 (2010).

17. Shin, S. et al. Layer-by-layer assembly of 3D tissue constructs with functionalized graphene. Adv. Funct. Mater. 24, 6136-6144 (2014).

18. Goenka, S., Sant, V. \& Sant, S. Graphene-based nanomaterials for drug delivery and tissue engineering. J. Control. Release 173, 75-88 (2014).

19. Park, D. et al. Graphene-based carbon-layered electrode array technology for neural imaging and optogenetic applications. Nat. Comm. 5, 5258 (2014).

20. Lu, Z., Mao, C. \& Zhang, H. Highly conductive graphene-coated silk fabricated via a repeated coating-reduction approach. J. Mater. Chem. C. 3, 4265-4268 (2015).

21. Aznar-Cervantes, S. et al. Electrospun silk fibroin scaffolds coated with reduced graphene promote neurite outgrowth of PC-12 cells under electrical stimulation. Mater. Sci. Eng. C. Mater. Biol. Appl. 79, 315-325 (2017).

22. Han, K. I. et al. Compliment graphene oxide coating on silk fiber surface via electrostatic force for capacitive humidity sensor applications. Sensors 17, 407 (2017).

23. Shah, S. et al. Guiding stem cell differentiation into oligodendrocytes using graphene-nanofiber hybrid scaffolds. Adv. Mater. 26, 3673-3680 (2014).

24. Zhang, X., Baughman, C. B. \& Kaplan, D. L. In vitro evaluation of electrospun silk fibroin scaffolds for vascular cell growth. Biomaterials 29, 2217-2227 (2008).

25. Jr, W. S. H. \& Offeman, R. E. Preparation of graphitic oxide. J. Am. Chem. Soc. 80, 1339 (1958).
26. Xu, F., Beyazoglu, T., Hefner, E., Gurkan, U. A. \& Demirci, U. Automated and adaptable quantification of cellular alignment from microscopic images for tissue engineering applications. Tissue Eng. C. Methods 17, 641 (2011).

27. Ramesha, G. K. \& Sampath, S. Electrochemical reduction of oriented graphene oxide films: an in situ Raman Spectroelectrochemical Study. J. Phys. Chem. C 113, 7985-7989 (2009).

28. Huang, L., Li, C., Yuan, W. \& Shi, G. Strong composite films with layered structures prepared by casting silk fibroin-graphene oxide hydrogels. Nanoscale 5, 3780-3786 (2013).

29. Le, J. L. \& Bažant, Z. P. Scaling of static fracture of quasi-brittle structures: strength, lifetime, and fracture kinetics. J. Appl. Mech. 79, 1006 (2012).

30. Bearinger, J. P., Hubbell, J. A., Napoli, A., Textor, M., Tirelli, N. Coating hydrophobic surfaces with amphiphilic thioethers to reduce protein adsorption and cell adhesion (2008).

31. Shin, S. R. et al. Reduced graphene oxide-GelMA hybrid hydrogels as scaffolds for cardiac tissue engineering. Small 12, 3677-3689 (2016).

32. Annabi, N. et al. Highly elastic micropatterned hydrogel for engineering functional cardiac tissue. Adv. Funct. Mater. 23, 4950-4959 (2013).

33. Solaro, R. J., Warren, C. M. \& Scruggs, S. B. Why is it important to analyze the cardiac sarcomere subproteome? Expert Rev. Proteom. 7, 311-314 (2010).

34. Kempen, M. J. V., Fromaget, C., Gros, D., Moorman, A. F. \& Lamers, W. H. Spatial distribution of connexin43, the major cardiac gap junction protein, in the developing and adult rat heart. Circ. Res. 68, 1638-1651 (1991).

35. Sakai, N., Tabb, T., Hertzberg, E. L., Hiroi, M. \& Garfield, R. E. Studies of connexin 43 and cell-to-cell coupling in cultured human myometrial cells. Prog. Cell Res. 4, 171-180 (1995).

36. Takahiro, H. A., Akihiro, I. B. \& Kenichi, Y. B. Contraction-induced cluster formation in cardiac cell culture. Phys. D. 237, 2787-2796 (2008)

37. Ypey, D. L, Meerwijk, W. P. M. V. \& Dehaan, R. L. Synchronization of Cardiac Pacemaker Cells by Electrical Coupling.(Springer: Netherlands, 1982.

38. Rook, M. B., Jonge, B. D., Jongsma, H. J. \& Masson-Pévet, M. A. Gap junction formation and functional interaction between neonatal rat cardiocytes in culture: a correlative physiological and ultrastructural study. J. Membr. Biol. 118 179-192 (1990).

39. Serena, E. et al. Electrical stimulation of human embryonic stem cells: cardiac differentiation and the generation of reactive oxygen species. Exp. Cell Res. 315, 3611-3619 (2009).

40. Sommer, J. R. \& Johnson, E. A. Cardiac muscle. A comparative study of Purkinje fibers and ventricular fibers. J. Cell. Biol. 36, 497-526 (1968). 